\begin{tabular}{|l|l|l|l|l|l|} 
J. Tek. Ling & Vol.11 & No.3 & Hal. 503 - 509 & Jakarta, September 2010 & ISSN 1441-318X \\
\hline
\end{tabular}

\title{
RESPON PUPUK DAUN NPK \\ TERHADAP PERTUMBUHAN Nepenthes ventrata DAN Nepenthes neglecta
}

\author{
Muhammad Mansur, Saefudin dan Fauzia Syarif \\ Peneliti di Bidang Botani, Pusat Penelitian Biologi \\ Lembaga IImu Pengetahuan Indonesia
}

\begin{abstract}
Leaf NPK fertilizer experiments on pitcher plant (Nepenthes neglecta and ventrata) conducted in May 2008 to March 2009 in a greenhouse, Botany Division, Research Center for BiologyLIPI, Cibinong Science Center, Cibinong. The objective is to study the effect of leaves NPK fertilizer on the growth of the two Nepenthes species tested. Experiments using Random Complete Factorial Design with two factors, namely the two Nepenthes species and three doses of fertilizer each treatment repeated six times. Growth parameters measured include; long shoot leaves, plant height, number of leaves, number of mature pitchers and growth pitchers. Results showed that the dose of NPK fertilizer provided (2 and $4 \mathrm{ml} / \mathrm{lt}$ ) have no effect on plant height and number of leaves, but little effect on the number of mature pitchers than the control plants. The statistical tests also showed no interaction between the two Nepenthes species with a given dose of fertilizer on the growth of plants. Minimum-maximum temperature recorded in the greenhouse during the experiment was $22.2^{\circ} \mathrm{C}$ and $38.5^{\circ} \mathrm{C}$. Meanwhile, air humidity between 43,6-64,7\%.
\end{abstract}

Key words: Leaf NPK fertilizer, plant growth, pitcher plant

\section{PENDAHULUAN}

\subsection{Latar Belakang}

Nepenthes(Kantong semar) digolongkan ke dalam tanaman hias unik, karena memiliki kantong yang dapat menjebak serangga dan binatang kecil lainnya untuk mensuplai kebutuhan nutrisinya. Sampai saat ini di dunia tercatat kurang lebih ada 93 jenis Nepenthes ${ }^{1)}$, yang tersebar mulai dari Madagascar, China bagian selatan, Asia Tenggara, Australia bagian utara sampai New Caledonia. Jumlah ini setiap tahunnya akan bertambah dengan ditemukannya jenis-jenis baru. Sampai dengan tahun 2006, Indonesia memiliki kurang lebih 64 jenis Nepenthes yang tersebar mulai dari Pulau
Sumatera hingga Irian Jaya ${ }^{2}$. Pada tahun 2010, jumlah tersebut bertambah menjadi 69 jenis dengan diketemukannya 5 jenis baru, seperti; Nepenthes adrianii dari Jawa Tengah ${ }^{3)}$, Nepenthes jamban dari Sumatera ${ }^{4)}$, Nepenthes flava dari Sumatera ${ }^{5}$, Nepenthes naga dari Sumatera6) dan Nepenthes pitopangii dari Sulawesi Tengah ${ }^{7}$.

Budidaya Nepenthes merupakan salah satu upaya pelestarian dan konservasi untuk menekan penurunan keanekaragaman jenis maupun populasinya di alam. Selain itu juga untuk menyediakan kebutuhan konsumen yang semakin bertambah jumlahnya setiap tahunnya, sehingga eksploitasi berlebihan di habitatnya dapat dikurangi. 
Sejak tahun 2005, Nepenthes mulai populer di Indonesia sebagai tanaman hias yang unik dan sejak itu tumbuhan memanjat ini mulai dibudidayakan oleh segelintir orang. Di alam, tumbuhan ini biasa hidup di tempattempat gersang yang umumnya miskin unsur hara, seperti; hutan gambut, hutan kerangas, rawa, gunung kapur, dan lain sebagainya. Berlatar belakang tempat hidupnya di alam, maka pemupukan pada Nepenthes menjadi pro-kontra dibicarakan oleh pembudidaya.

Moran melaporkan bahwa Nepenthes yang hidup liar di alam dan banyak menjebak serangga di dalam kantongnya terlihat hidup lebih sehat dan kuat, ukuran kantong lebih besar dan warna kantong lebih cerah dari pada Nepenthes yang sedikit berisi serangga di dalam kantongnya ${ }^{8)}$. Namun jika Nepenthes yang dibudidayakan diberi pupuk dalam jumlah besar, mungkin pertumbuhannya akan baik, namun kantong yang dihasilkan akan sedikit, bahkan produksi kantong terhenti9). Oleh karena itu perlu adanya keseimbangan di dalam pemberian pupuk agar dapat mendorong pertumbuhan dan produksi kantong.

\subsection{Tujuan}

Tujuan dari penelitian ini adalah untuk mempelajari dan mengetahui pengaruh pemupukan NPK dan dosis yang tepat pada pertumbuhan Nepenthes, khususnya pada jenis $N$. ventrata dan $N$. neglecta.

\section{METODOLOGI}

Penelitian dilakukan selama 10 bulan dari bulan Mei 2008 sampai dengan bulan Maret 2009, di kamar kaca, Bidang Botani, Puslit Biologi-LIPI, Cibinong Science Center, Cibinong.

\subsection{Bahan dan Alat}

Dua jenis Nepenthes digunakan sebagai bahan penelitian, yakni; N. neglecta dan $N$. ventrata. $N$. neglecta merupakan jenis hasil silang alami dari $N$. gracilis dan N. mirabilis (Asal Indonesia). Sedangkan $N$. ventrata hasil silang alami dari $N$. ventricosa dan N. alata (Asal Filippina). Pupuk daun NPK menggunakan komposisi; $\mathrm{N}=32 \%$, $\mathrm{P}=20 \%$ dan $\mathrm{K}=20 \%$. Untuk mengukur suhu dan kelembaban udara digunakan alat Thermometer maximum-minimum dan hygrometer. Sedangkan untuk mengurangi intensitas cahaya digunakan paranet berukuran $50 \%$ yang dipasang di luar atap dan di dalam kamar kaca.

Penelitian menggunakan Rancangan Acak Lengkap Faktorial dengan enam kali ulangan. Faktor pertama adalah dua jenis Nepenthes, yakni $N$. neglecta dan $N$. ventara. Sedangkan faktor kedua adalah tiga dosis pupuk daun NPK, yakni; kontrol (tanpa pupuk), $2 \mathrm{ml} / \mathrm{lt}$ dan $4 \mathrm{ml} / \mathrm{lt}$. Parameter yang di amati adalah; panjang tunas daun, tinggi tanaman, jumlah daun, jumlah kantong dewasa (tutup kantong terbuka) dan pertumbuhan kantong. Penanaman menggunakan dengan cara setek batang dua buku $(8-9 \mathrm{~cm})$ untuk $N$. neglecta dan dua buku $(6-8 \mathrm{~cm})$ untuk jenis $N$. ventrata. Bahan setek ditanam pada pot plastik berdiameter $10 \mathrm{~cm}$ yang diisi cocopeat sebanyak kurang lebih 83 gram/pot. Penyiraman dilakukan setiap 4 empat hari sekali, sedangkan perlakuan pemupukan dilakukan dengan cara penyemprotan terhadap seluruh daun secara merata pada pagi hari dan setiap tujuh hari sekali. Suhu dan kelembaban udara di dalam kamar kaca dicatat setiap hari kerja pada pagi hari (jam 8.00-9.00), siang hari (12.00-13.00) dan sore hari (15.00-16.00).

\section{HASIL DAN PEMBAHASAN}

\subsection{Hasil}

\section{1) Tunas Daun}

Tunas daun mulai tumbuh di ketiak daun pada jenis $N$. ventrata setelah 19 hari setelah tanam, sedangkan pada $N$. neglecta 
belum terlihat ada pertumbuhan tunas daun. Setelah 4 minggu setelah tanam (MST), jenis $N$. ventrata seluruhnya sudah bertunas. Tunas daun terpanjang $(6 \mathrm{~mm})$ terlihat pada perlakuan pupuk $2 \mathrm{ml} / \mathrm{tt}\left(\mathrm{V}_{2}\right)$, diikuti oleh perlakuan $4 \mathrm{ml} / \mathrm{lt}\left(\mathrm{V}_{4}\right)$ sepanjang $3 \mathrm{~mm}$ dan kontrol (Vo) sepanjang 2,33 mm. Sedangkan pada jenis $N$. neglecta, tunas daun terlihat baru tumbuh pada kontol (No) sepanjang $0,17 \mathrm{~mm}$. Setelah $10 \mathrm{MST}$, hampir seluruh tanaman N. neglecta sudah memperlihatkan mata tunas pada seluruh perlakuan. Panjang mata tunas tertinggi justru pada kontrol (No) yakni sepanjang $18,17 \mathrm{~mm}$, diikuti oleh $\mathrm{N}_{4}$ (dosis $4 \mathrm{ml} / \mathrm{lt}$ ) $=15,83 \mathrm{~mm}$ dan $\mathrm{N}_{2}$ (dosis $2 \mathrm{ml} / \mathrm{lt})=9,5 \mathrm{~mm}$. Pertumbuhan mata tunas dari kedua jenis Nepenthes tersebut di atas dapat dilihat pada diagram 1 .

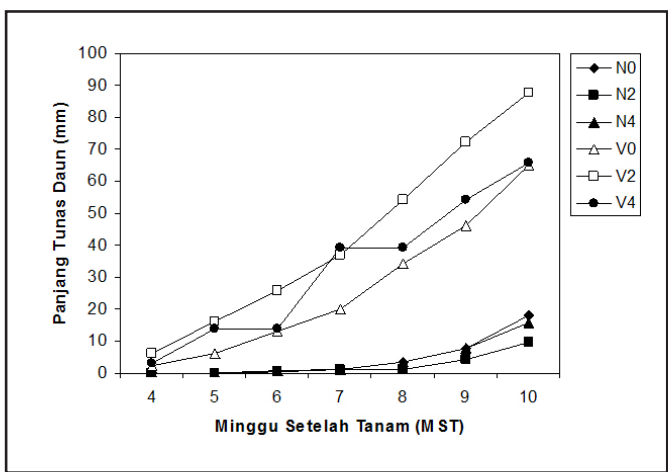

Diagram1. Respon pupuk daun NPK terhadap panjang tunas daun pada $N$. neglecta dan $N$. ventrata dari mulai $4 \mathrm{MST}$ hingga 10 MST.

Keterangan:

$\mathrm{N} 0=$ Neglecta tanpa pupuk.

$\mathrm{N} 2=$ Neglecta + pupuk $2 \mathrm{ml} / \mathrm{lt}$.

$\mathrm{N} 4=$ Neglecta + pupuk $4 \mathrm{ml} / \mathrm{lt}$.

$\mathrm{V} 0=$ Ventrata tanpa pupuk.

$\mathrm{V} 2=$ Ventrata + pupuk $2 \mathrm{ml} / \mathrm{lt}$.

$\mathrm{V} 4=$ Ventrata + pupuk $4 \mathrm{ml} / \mathrm{t}$.

\section{2) Tinggi Tanaman}

Secara umum, seluruh dosis pemupukan $(0 ; 2 ; 4 \mathrm{ml} / \mathrm{lt})$ tidak berpengaruh terhadap tinggi tanaman, baik itu pada $N$. neglecta maupun pada $N$. ventrata mulai dari 21 MST hingga 41 MST. Namun demikian di akhir pengamatan (41 MST) jenis $N$. ventrata sedikit lebih tinggi dari pada $N$. neglecta, meskipun secara statistik tidak berbeda nyata. Pertumbuhan tinggi tanaman dari kedua jenis pada masing-masing dosis pemupukan dapat dilihat pada Gambar 2.

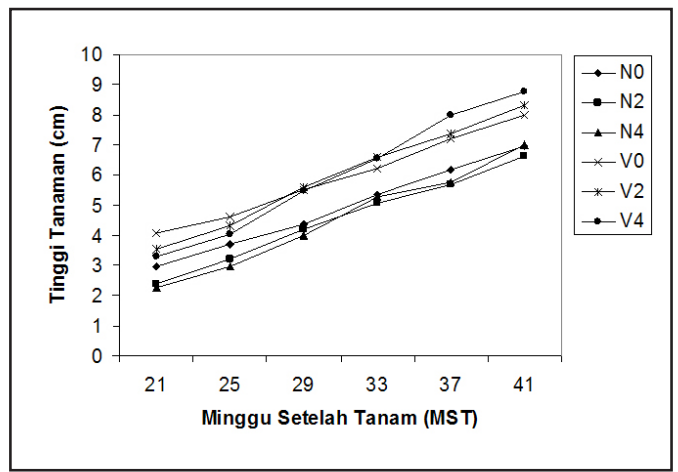

Diagram 2. Respon pupuk daun NPK terhadap tinggi tanaman pada $N$. neglecta dan $N$. ventrata dari mulai 21 MST hingga 41 MST.

Keterangan:

$\mathrm{N} 0=$ Neglecta tanpa pupuk.

$\mathrm{N} 2=$ Neglecta + pupuk $2 \mathrm{ml} / \mathrm{lt}$.

$\mathrm{N} 4=$ Neglecta + pupuk $4 \mathrm{ml} / \mathrm{lt}$.

$\mathrm{V} 0=$ Ventrata tanpa pupuk.

$\mathrm{V} 2=$ Ventrata + pupuk $2 \mathrm{ml} / \mathrm{lt}$.

$\mathrm{V} 4=$ Ventrata + pupuk $4 \mathrm{ml} / \mathrm{lt}$

\section{3) Jumlah Daun}

Dosis pemupukan juga tidak berpengaruh terhadap jumlah daun dari masing-masing jenis yang diamati, mulai dari 15 MST hingga $41 \mathrm{MST}$, namun demikian jumlah daun berbeda nyata pada kedua jenis Nepenthes, yakni $N$. neglecta memiliki rata-rata sebesar 9 daun dan $N$. ventrata 12 daun (Gambar 3 dan Tabel 1).

\section{4) Jumlah Kantong Dewasa}

Jenis $N$. ventrata memiliki jumlah kantong sedikit lebih banyak dari pada $N$. neglecta, berturut-turut sejumlah 4,65 dan 
3,39 kantong dan hasil uji Duncan berbeda nyata pada taraf $5 \%$. Demikian pula dosis pemupukan menunjukkan hasil berbeda nyata dari pada kontrol terhadap jumlah kantong dewasa, yakni; kontrol (No) tercatat $3,17, \mathrm{~N}_{2}=4,67$ dan $\mathrm{N}_{4}=4,18$ kantong (Gambar 4 dan Tabel 1).

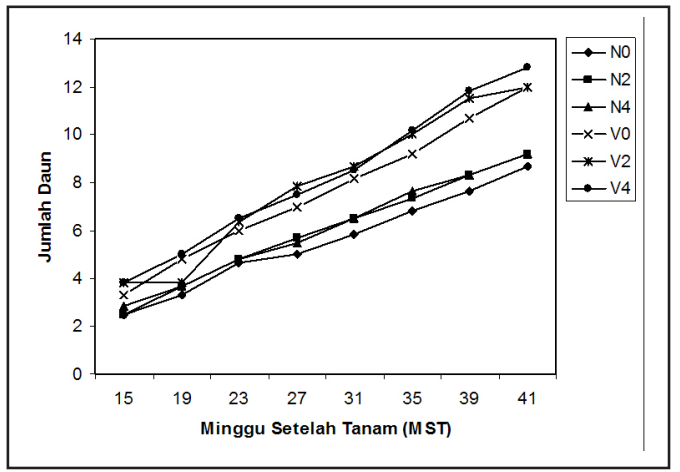

Diagram 3. Respon pupuk daun NPK terhadap jumlah daun pada $N$. neglecta dan $N$. ventrata dari mulai 15 MST hingga 41 MST.

Keterangan:

$\mathrm{N} 0=$ Neglecta tanpa pupuk.

$\mathrm{N} 2=$ Neglecta + pupuk $2 \mathrm{ml} / \mathrm{lt}$.

$\mathrm{N} 4=$ Neglecta + pupuk $4 \mathrm{ml} / \mathrm{tt}$.

$\mathrm{V} 0=$ Ventrata tanpa pupuk.

V2= Ventrata + pupuk $2 \mathrm{ml} / \mathrm{lt}$.

V4= Ventrata + pupuk $4 \mathrm{ml} / \mathrm{lt}$.

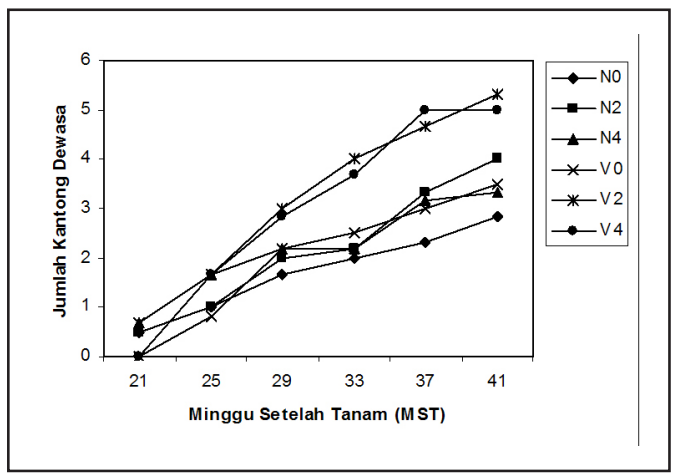

Diagram 4. Respon pupuk daun NPK terhadap jumlah kantong dewasa pada $N$. neglecta dan $N$. ventrata dari mulai 21 MST hingga $41 \mathrm{MST}$.
Keterangan:

$\mathrm{N} 0=$ Neglecta tanpa pupuk.

$\mathrm{N} 2=$ Neglecta + pupuk $2 \mathrm{ml} / \mathrm{lt}$.

$\mathrm{N} 4=$ Neglecta + pupuk $4 \mathrm{ml} / \mathrm{lt}$.

$\mathrm{V} 0=$ Ventrata tanpa pupuk.

$\mathrm{V} 2=$ Ventrata + pupuk $2 \mathrm{ml} / \mathrm{t}$.

V4= Ventrata + pupuk $4 \mathrm{ml} / \mathrm{lt}$

\section{5) Interaksi}

Dari hasil uji statistik menunjukkan bahwa tidak ada interaksi dari jenis $N$. neglecta dengan dosis pemupukan terhadap tinggi tanaman, jumlah daun maupun jumlah kantong dewasa. Demikian pula pada jenis $N$. ventrata terhadap parameter tinggi tanaman dan jumlah daun. Namun pada jumlah kantong dewasa terlihat adanya interaksi antara $N$. ventara dengan dosis pemupukan. Dari data yang ada terlihat bahwa dosis pemupukan merespon jumlah kantong dewasa dibandingkan dengan kontrol, meskipun di antara dosis $2 \mathrm{ml} /$ It dan $4 \mathrm{ml} / \mathrm{lt}$ terlihat tidak ada perbedaan (Tabel 2).

\section{6) Pertumbuhan Kantong}

Pertumbuhan kantong diukur pada saat bakal kantong terbentuk hingga tutup kantong (Lid) terbuka. Bakal kantong mulai terbentuk pada 21 MST. Dari diagram 5 terlihat bahwa pola pertumbuhan kantong $N$. neglecta dan $N$. ventrata hampir sama. Namun demikian $N$. neglecta memiliki ukuran kantong lebih tinggi $(7,1 \mathrm{~cm})$ daripada $N$. ventrata $(5,9 \mathrm{~cm})$ pada saat umur kantong 30 hari. Pada umumnya tutup kantong terbuka (kantong dewasa) tercatat pada umur 2030 hari terhitung dari saat bakal kantong terbentuk. Laju pertambahan ukuran tinggi kantong berkurang setelah tutup kantong mulai terbuka. Ukuran kantong semakin tinggi dan besar pada setiap daun yang tumbuh berikutnya. 
Tabel 1. Analisa statistik pertumbuhan dua jenis Nepenthes terhadap beberapa dosis pupuk NPK pada umur 10 bulan.

\begin{tabular}{|l|c|c|c|}
\hline Perlakuan & Tinggi (cm) & Jumlah daun & Jumlah kantong \\
\hline Jenis Nepenthes & \multicolumn{3}{|l|}{} \\
\hline Neglecta (N) & $6.88 \mathrm{a}$ & $9.00 \mathrm{~b}$ & $3.39 \mathrm{~b}$ \\
\hline Ventrata (V) & $8.14 \mathrm{a}$ & $12.12 \mathrm{a}$ & $4.65 \mathrm{a}$ \\
\hline Dosis Pupuk NPK & $7.48 \mathrm{a}$ & $10.33 \mathrm{a}$ & $3.17 \mathrm{~b}$ \\
\hline $0 \mathrm{ml} / \mathrm{lt}$ & $7.51 \mathrm{a}$ & $10.58 \mathrm{a}$ & $4.67 \mathrm{a}$ \\
\hline $2 \mathrm{ml} / \mathrm{lt}$ & $7.46 \mathrm{a}$ & $10.64 \mathrm{a}$ & $4.18 \mathrm{a}$ \\
\hline $4 \mathrm{ml} / \mathrm{lt}$ &
\end{tabular}

Keterangan: Angka yang diikuti huruf yang sama pada kolom yang sama menunjukan tidak berbeda nyata pada taraf $5 \%$ dengan uji Duncan.

\begin{tabular}{|l|c|c|c|}
\hline Interaksi & $\begin{array}{c}\text { Tinggi tanaman } \\
(\mathbf{c m})\end{array}$ & Jumlah Daun & $\begin{array}{c}\text { Jumlah Kantong } \\
\text { Dewasa }\end{array}$ \\
\hline Nepenthes+Pupuk & & & \\
\hline Neglecta (N) + Pupuk & & & $2.83 \mathrm{a}$ \\
\hline $\mathrm{N}+$ Kontrol & $6.97 \mathrm{a}$ & $8.67 \mathrm{a}$ & $4,00 \mathrm{a}$ \\
\hline $\mathrm{N}+2 \mathrm{ml} / \mathrm{lt}$ & $6.62 \mathrm{a}$ & $9.17 \mathrm{a}$ & $3.33 \mathrm{a}$ \\
\hline $\mathrm{N}+4 \mathrm{ml} / \mathrm{lt}$ & $7.00 \mathrm{a}$ & $9.17 \mathrm{a}$ & \\
\hline & & & $3.50 \mathrm{~b}$ \\
\hline Ventrata (V) + Pupuk & & & $5.33 \mathrm{a}$ \\
\hline $\mathrm{V}+$ kontrol & $7.98 \mathrm{a}$ & $12.00 \mathrm{a}$ & $5.20 \mathrm{a}$ \\
\hline $\mathrm{V}+2 \mathrm{ml} / \mathrm{lt}$ & $8.40 \mathrm{a}$ & $12.00 \mathrm{a}$ & $12.40 \mathrm{a}$ \\
\hline $\mathrm{V}+4 \mathrm{ml} / \mathrm{lt}$ & $8.00 \mathrm{a}$ & & \\
\hline
\end{tabular}

Keterangan: Angka yang diikuti huruf yang sama pada kolom yang sama menunjukan tidak berbeda nyata pada taraf $5 \%$ dengan uji Duncan.

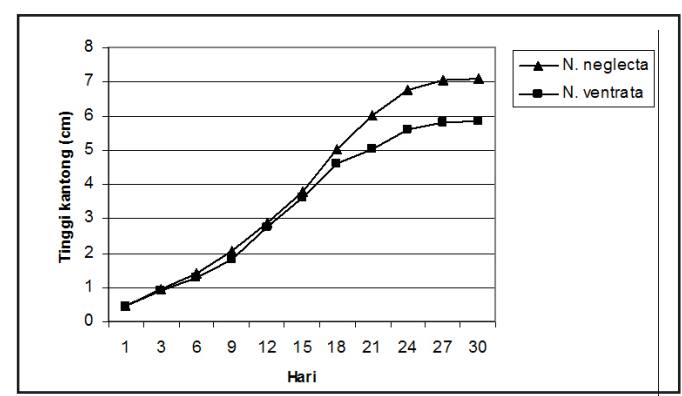

Diagram 5. Pertumbuhan tinggi kantong $N$. neglecta dan $N$. ventrata

\section{7) Suhu dan Kelembaban Udara}

Suhu maksimum tertinggi tercatat pada bulan September, yakni rata-rata $38,5^{\circ} \mathrm{C}$, sedangkan suhu minimum terendah $22,2^{\circ} \mathrm{C}$ yaitu pada bulan Juli (Diagram 6). Suhu udara pada siang hari (pagi, siang dan sore) rata-rata di antara $28,2^{\circ} \mathrm{C}-33,5^{\circ} \mathrm{C}$ dan kelembaban udara di antara $43,6 \%-64,7 \%$.

Data tersebut di atas adalah data yang terukur di dalam rumah kaca yang pada umumnya lebih tinggi $1-2^{\circ} \mathrm{C}$ daripada di luar rumah kaca. Kenaikan ini disebabkan karena efek rumah kaca. Pada diagram 7 terlihat bahwa suhu udara pada siang hari terendah terjadi pada bulan Januari dan Februari dengan kelembaban udara lebih tinggi daripada bulanbulan lainnya. Dari data suhu harian yang tercatat bahwa suhu udara maksimum tertinggi yang pernah tercatat adalah $41^{\circ} \mathrm{C}$, yakni pada bulan September dengan angka kelembaban udara pada saat itu sebesar $33 \%$. 


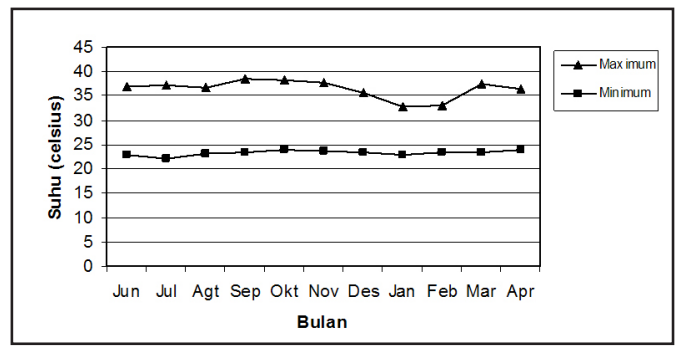

Diagram 6. Suhu udara maksimum dan minimum yang tercatat di dalam kamar kaca.

\subsection{Pembahasan}

Budidaya N. neglecta dan N. ventrata mudah dilakukan dengan cara setek batang. Dari hasil percobaan terlihat bahwa jumlah tanaman $100 \%$ bertunas pada N. ventrata setelah $4 \mathrm{MST}$, sedangkan $N$. neglecta jumlah tunas tumbuh $88,9 \%$ pada saat 10 MST. Percepatan tumbuh tunas daun pada kedua jenis yang diuji tidak dipengaruhi oleh perlakuan pemupukan hingga dosis $4 \mathrm{ml} / \mathrm{lt}$. Hal ini terbukti bahwa jumlah tanaman yang bertunas antara kontrol dan perlakuan tidak menunjukkan perbedaan.

Secara umum faktor dosis pupuk NPK (0;2;4 ml/lt) tidak menunjukkan adanya pengaruh terhadap parameter tinggi tanaman dan jumlah daun, namun sedikit berpengaruh pada jumlah kantong dewasa. Sebaliknya faktor jenis memperlihatkan adanya perbedaan nyata terhadap jumlah daun dan jumlah kantong dewasa, namun tidak pada tinggi tanaman. Jenis $N$. ventrata memiliki karakter tinggi tanaman, jumlah daun dan jumlah kantong dewasa lebih besar daripada $N$. neglecta (Tabel 1). Hal ini diperjelas dengan hasil uji statistik bahwa tidak adanya interaksi antara kedua jenis Nepenthes yang diuji dengan faktor dosis pupuk yang diberikan sampai dengan $4 \mathrm{ml} / \mathrm{lt}$ terhadap pertumbuhan tanaman (Tabel 2).

Ada dua kemungkinan yang menyebabkan tidak adanya respon pupuk NPK terhadap pertumbuhan tanaman pada kedua jenis Nepenthes yang diuji. Pertama, kemungkinan dosis pupuk yang diberikan

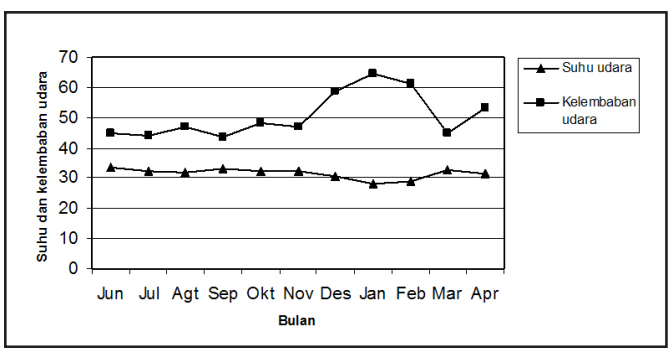

Diagram 7. Suhu dan kelembaban udara pada siang hari yang tercatat di dalam kamar kaca.

terlalu rendah sehingga tanaman belum merespon. Kedua, kemungkinan tanaman yang tidak diberi pupuk (kontrol) masih menerima nutrisi dari beberapa serangga (semut) yang terjebak di dalam kantongnya. Oleh karena itu pada percobaan selanjutnya, kantong pada seluruh tanaman Nepenthes yang diuji perlu ditutup mulut kantongnya, sehingga tidak ada lagi serangga yang masuk kantong. Dengan demikian seluruh tanaman hanya mendapatkan nutrisinya dari pupuk yang diberikan.

\section{KESIMPULAN}

Setek batang $N$. ventrata memiliki kecepatan bertunas, tinggi tanaman, jumlah daun dan jumlah kantong dewasa lebih besar daripada $N$. neglecta. Secara umum, dosis pemupukan NPK pada daun (2 dan $4 \mathrm{ml} / \mathrm{lt}$ ) tidak berpengaruh nyata terhadap tinggi tanaman dan jumlah daun pada kedua jenis Nepenthes yang diuji, namun berpengaruh nyata pada jumlah kantong dewasa. Pertumbuhan kantong sangat dipengaruhi oleh kondisi tanaman dan iklim mikro setempat, khususnya suhu udara, kelembaban udara dan intensitas cahaya. Budidaya $N$. neglecta dan $N$. ventrata sangat mudah dilakukan dengan cara setek batang. Pada suhu udara kisaran antara $22,2^{\circ} \mathrm{C}-38,5^{\circ} \mathrm{C}$ dan kelembaban udara 40 $64 \%$, Nepenthes dari jenis neglecta dan ventrata masih menunjukkan pertumbuhan yang cukup baik. Disarankan perlu adanya penelitian lanjutan dengan dosis pemupukan 
lebih tinggi dari $4 \mathrm{ml} /$ lt untuk $N$. neglecta. Sedangkan untuk $N$. ventrata cukup sampai dengan dosis $2 \mathrm{ml} / \mathrm{lt}$.

\section{DAFTAR PUSTAKA}

1. Mansur, M., F. Damayanti dan I. Roostika. 2009. Diversity of Nepenthes spp. In West Kalimantan. Joint Workshop JSPS International Training Program (ITP) and Ecological Society of Indonesia (HEI): To Protect Diversity of Bioresources in The Tropical Area. Bogor, 25-26 November 2009.

2. Mansur, M. 2006. Nepenthes: Kantong Semar Yang Unik. Penebar Swadaya, Jakarta. 99 halaman.

3. Batoro, 2006. Komunikasi Pribadi. Jurusan Biologi, FMIPA, Universitas Brawijaya, Malang.

4. Lee, C., Hernawati, dan P. Akhriadi. 2006. Two New Species of Nepenthes (Nepenthaceae) From North Sumatra. Blumea 51(3): 561-568.

5. Wistuba, A.J. Nerz dan A. Fleischmann. 2007. Nepenthes flava. A New Species of Nepenthaceae From The Northern Part of Sumatra. Blumea. 52:159-163.

6. Akhriadi, P., Hernawati, A. Primaldhi dan M. Hambali. 2008. Nepenthes naga, A New Species of Nepenthaceae From Bukit Barisan of Sumatra. Reinwardtia. 12(5): 339-342. Puslit Biologi-LIPI, Bogor.

7. Lee, C., S.R. Mcpherson, G. Bourke dan M. Mansur. 2009. Nepenthes pitopangii (Nepenthaceae), A New Species from Central Sulawesi, Indonesia. Gardens' Bulletin Singapore. 61(1): 95-99.

8. Moran, J.A. \& A.J. Moran. 1998. Foliar Reflectance and Vector Analysis Reveal Nutrient Stress in Prey-Deprived Pitcher Plants (Nepenthes rafflesiana). International Journal of Plant Sciences 159: 996-1001.

9. Clarke, C. 2001. Nepenthes of Sumatra and Peninsular Malaysia. Natural History Publication, Kota Kinabalu, Malaysia. 326 halaman

\section{LAMPIRAN FOTO}

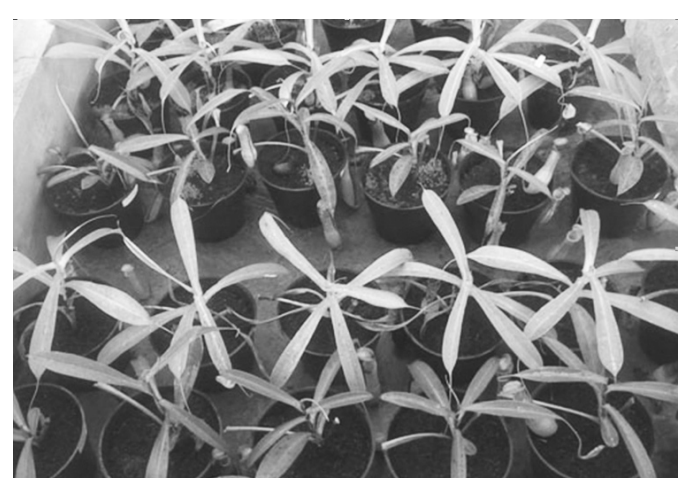

Gambar 1. N. neglecta dan N. ventrata pada umur 8 bulan.

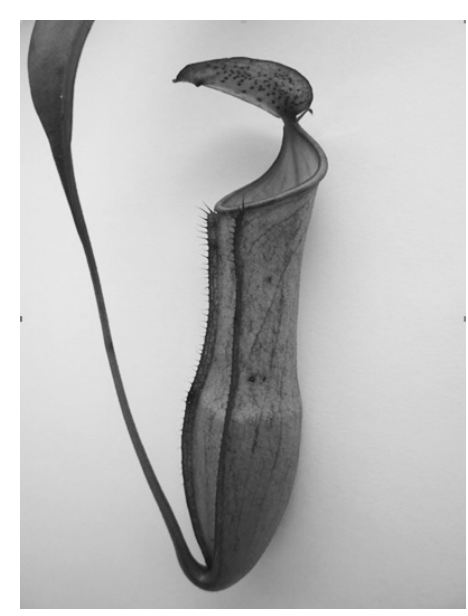

Gambar 2. Nepenthes neglecta

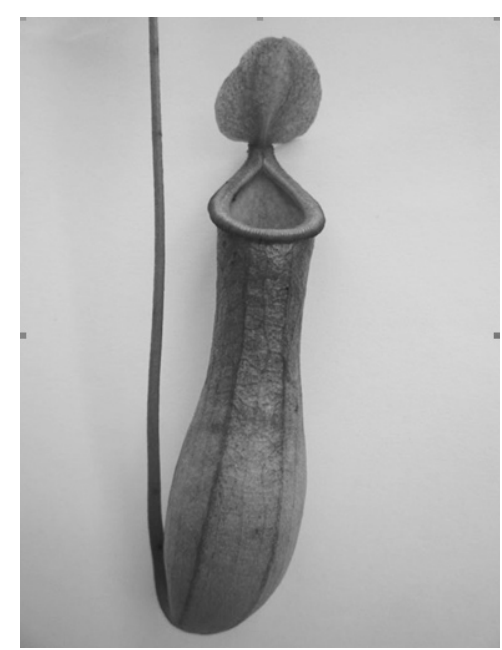

Gambar 3. Nepenthes ventrata 